\title{
Dois novos registros de distribuição geográfica em Epidendrum (Orchidaceae) para o Centro-Oeste brasileiro
}

Two new geographic distribution records in Epidendrum (Orchidaceae) for the Brasilian Central-West

\author{
Mathias Erich Engels ${ }^{1,3}$ \& Lilien Cristhiane Ferneda Rocha ${ }^{2}$
}

\begin{abstract}
Resumo
Este trabalho apresenta os novos registros de Epidendrum cristatum e E. macrocarpum para a região CentroOeste, no estado de Mato Grosso. São fornecidas descrições, dados de distribuição geográfica, informações taxonômicas e ecológicas, bem como uma prancha fotográfica das espécies estudadas.

Palavras-chave: Amazônia, epífita, orquídea, Região Neotropical.
\end{abstract}

\begin{abstract}
This work present the new records of Epidendrum cristatum and E. macrocarpum in the Central West region, in Mato Grosso state. We provided descriptions, geographic distribution data, taxonomic and ecological information, and photos of the species.
\end{abstract}

Key words: Amazon, epiphyte, orchid, Neotropical Region.

Epidendrum L. é um dos gêneros de Orchidaceae mais ricos da Região Neotropical, com cerca de 1500 espécies (Hagsáter \& SotoArenas 2005), e se distribui desde os Estados Unidos até a Argentina (Govaerts 2015). No Brasil é bastante expressivo, com 134 espécies ocorrendo em praticamente todo o território e no estado do Mato Grosso, encontra-se representado por 19 espécies (BFG 2015). Apresenta grande variação morfológica, tanto vegetativa quanto reprodutiva, sendo caracterizado pelo labelo adnato à coluna e pela antera dorso-apical (Hagsáter \& Soto-Arenas 2005).

Durante o resgate de Flora da Usina Hidrelétrica Colíder, que abrange os municípios de Cláudia, Colíder, Itaúba e Nova Canaã do Norte, região centro-norte de Mato Grosso, foi coletado material de E. cristatum Ruiz \& Pav. e E. macrocarpum Rich. Estas duas espécies são aqui registradas pela primeira vez para este estado, elevando para 21 o número de espécies do gênero. $\mathrm{O}$ material coletado foi herborizado segundo Fidalgo \& Bononi (1989) e depositado nos herbários HERBAM e MBM (acrônimos de acordo com Thiers [continuamente atualizado]).
Deste modo, o presente trabalho tem o intuito de apresentar estes novos registros para o Mato Grosso, ampliando a distribuição destas espécies no território nacional, além de trazer descrições, dados de distribuição geográfica, comentários taxonômicos e ecológicos, e uma prancha com fotografias.

Epidendrum cristatum Ruiz \& Pav., Syst. Veg. Fl. Peruv. Chil.: 243. $1798 . \quad$ Fig. 1a-d

Erva epífita, cespitosa. Raízes $2-4 \mathrm{~mm}$ espessura, castanho alvacentas. Rizoma ca. 1 $\mathrm{cm}$ espessura, cilíndrico, 1-1,4 cm entre caules secundários, castanho. Cauloma 80-100× $0,7-0,8 \mathrm{~cm}$, colmoso, cilíndrico, verde. Folhas alternas, conduplicadas; bainha 4-4,5 × 1,8-2,4 $\mathrm{cm}$, oblonga, amplexicaule, verde; limbo 20,3$22,5 \times 2,7-3,6 \mathrm{~cm}$, estreito elíptico, base aguda, ápice agudo a obtuso, margem inteira, verde. Inflorescência em racemo simples, terminal, pendente, 17-26-flora, com brácteas imbricadas na base; brácteas do pedúnculo 10-14,2 × 1,4-1,6 $\mathrm{cm}$, estreito triangulares, base truncada, ápice arredondado, margem inteira, verdes; pedúnculo 13-13,5 × 0,4-0,5 cm, subcilíndrico, verde; raque

\footnotetext{
${ }^{1}$ Assessoria Técnica Ambiental Ltda., R. Marechal José Bernardino Bormann 821, Batel, 80730-350, Curitiba, PR, Brasil

${ }^{2}$ Juris Ambientis Consultores S S Ltda., R. Humberto Carta 96, Hugo Lange, 80040-150, Curitiba, PR, Brasil.

${ }^{3}$ Autor para correspondência: mathiasengels@hotmail.com
} 


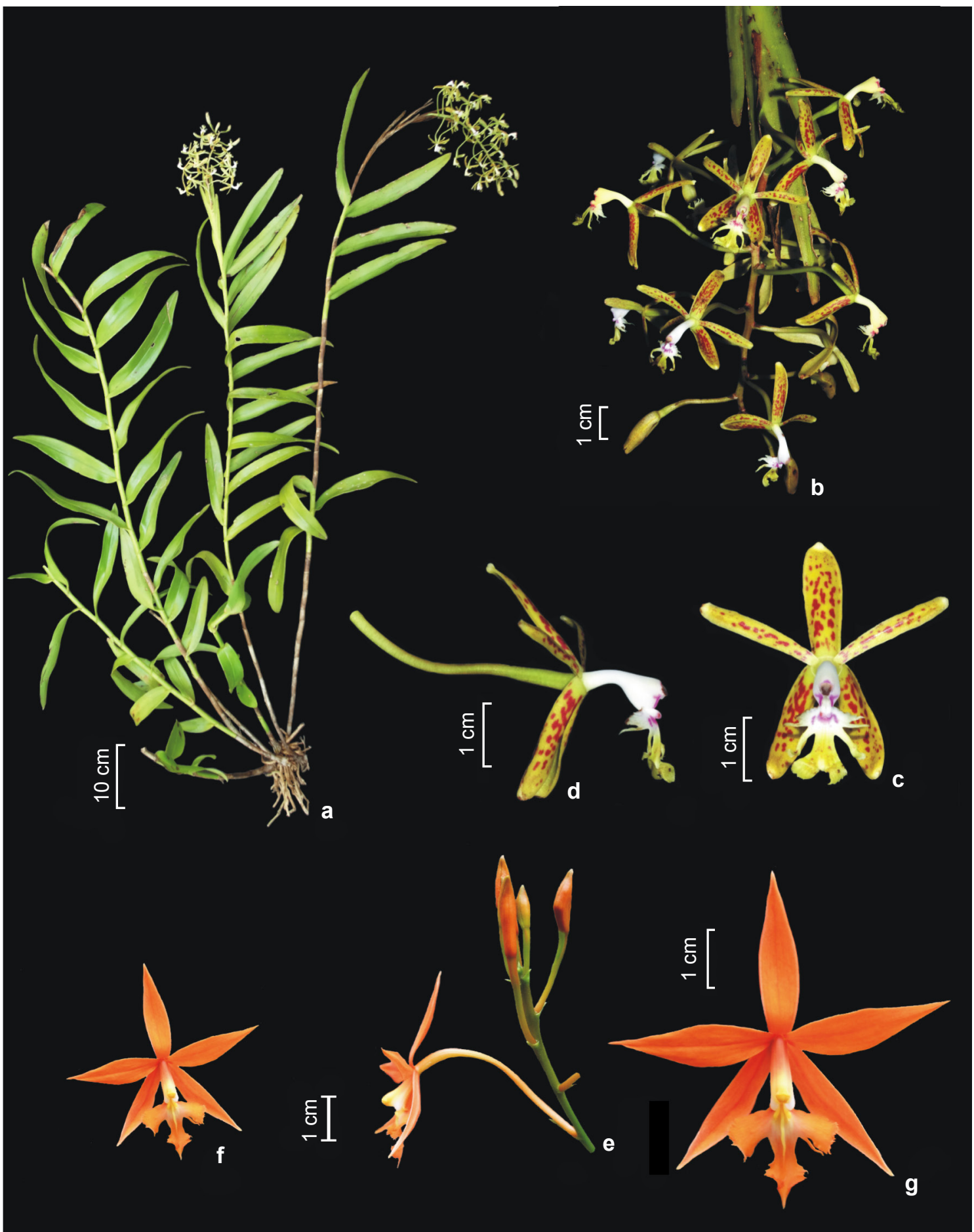

Figura 1 - a-d. Epidendrum cristatum Ruiz \& Pav. - a. hábito; b. inflorescência; c-d. flor; c. vista frontal; d. vista lateral. e-g. Epidendrum macrocarpum Rich. - e. inflorescência; f-g. flor em vista frontal. Fotos: M.E.Engels.

Figure 1 - a-d. Epidendrum cristatum Ruiz \& Pav. - a. habit; b. inflorescence; c-d. flower; c. frontal view; d. lateral view. e-g. Epidendrum macrocarpum Rich. - e. inflorescence; f-g. frontal view of flower. Photos: M.E.Engels. 
$10,5-15 \times 0,2-0,3 \mathrm{~cm}$, cilíndrica, verde a verdeacastanhada. Flor ressupinada; ovário + pedicelo $3,2-4 \times 0,2 \mathrm{~cm}$, cilíndrico, sulcado, verde; sépala dorsal ca. 1,8 $\times 0,5 \mathrm{~cm}$, elíptica a lanceolada, base aguda, ápice obtuso, margem inteira, verde-claro com pintas castanhas; sépalas laterais ca. 1,8 $\times 0,5$ $\mathrm{cm}$, elípticas, base aguda, ápice obtuso, margem inteira, verde-claro com pintas castanhas; pétalas ca. $1,8 \times 0,2 \mathrm{~cm}$, estreitamente oblanceoladas, base aguda, ápice obtuso a arredondado, margem inteira, verde-claro com pintas castanhas; labelo ca. $1,8 \times 1 \mathrm{~cm}$, trilobado, com uma par de calos na base do disco central; lobos laterais subquadrados, margem profundamente fimbriada, alvos; lobo central obdeltoide, ápice retuso, margem serreadodenticulado, nervura central espessada da base do disco central ao ápice do lobo central, verde-claro alvacento; calos 2 , ca. $2 \times 0,5 \mathrm{~mm}$, elípticos, alvos com ápice róseo. Coluna 1,2 × 0,4 $\mathrm{cm}$, adnata ao labelo, claviforme, alva com margem do estigma rosada. Antera $1 \times 1 \mathrm{~mm}$, arredondada, alva. Polínias 4, ca. $1 \mathrm{~mm}$ compr., obovoides, fortemente achatadas, amarelas. Fruto não visto. Material examinado: BRASIL. MATO GROSSO: Itaúba, Resgate de Flora da UHE Colíder, lote $\mathrm{G}$ de supressão, 2.XI.2015, fl., M.E.Engels 3752 (HERBAM, MBM).

Epidendrum cristatum possui ampla distribuição na Região Neotropical: México, Belize, Costa Rica, Guatemala, Honduras, Nicarágua, Panamá, Trindade e Tobago, Guiana, Suriname, Venezuela, Bolívia, Colômbia, Equador, Peru e Brasil (Govaerts 2015). No Brasil ocorre nos estados das regiões Sudeste e Sul, além da Bahia (BFG 2015). A possível ocorrência desta espécie para a Região Norte é apontada por BFG (2015), provavelmente devido a indicação de Silva et al. (1995) para o Pará e Roraima, no entanto, sem discriminarem material testemunho. No presente trabalho, E. cristatum tem sua distribuição ampliada para a região Centro-Oeste, no estado de Mato Grosso. Foi encontrada como epífita na Floresta Estacional Sempre Verde, às margens do rio Teles Pires, região de ecótono entre os domínios do Cerrado e Amazônia, sendo pouco frequente. Encontrada com flor em novembro.

Esta espécie é bastante característica por apresentar porte robusto com caule podendo chegar a $1 \mathrm{~m}$ de comprimento. Além disso, sua inflorescência é racemosa, simples e pendente, protegida na base por brácteas imbricadas, com flores de pétalas e sépalas verde-claras, com pintas castanhas; labelo alvo e verde-claro, trilobado com lobos laterais profundamente fimbriados.
Epidendrum macrocarpum Rich., Actes Soc. Hist. Nat. Paris 1: 112. $1792 . \quad$ Fig. 1e-g Erva epífita, cespitosa. Raízes ca. $2 \mathrm{~mm}$ espessura, alvo acastanhadas. Rizoma ca. 5 $\mathrm{mm}$ espessura, cilíndrico, ca. $1 \mathrm{~cm}$ entre caules secundários, castanho. Cauloma 40-80 × 0,5 $\mathrm{cm}$, colmoso, cilíndrico, verde. Folhas alternas, conduplicadas; bainha 2,4-4 ×0,6-0,8 cm, oblonga, amplexicaule, verde; limbo 11-16,5 × 1,9-2,86 cm, elíptico; base aguda, ápice agudo, margem inteira, verde. Inflorescência em racemo simples, terminal, ascendente, 5-6-flora, com brácteas amplectivas dispersas no pedúnculo; brácteas do pedúnculo 4,4-11,6 × 0,8-1 cm, oblongo-elipsoides, base truncada, ápice agudo, margem inteira, verdes; pedúnculo $24 \times 0,3 \mathrm{~cm}$, cilíndrico, verde; raque $2,7 \times 0,2 \mathrm{~cm}$, cilíndrica, verde. Flor ressupinada; ovário + pedicelo 3,8-4,0 $\times 0,1-0,2 \mathrm{~cm}$, cilíndricos, sulcado, verde-alaranjado; sépala dorsal ca. $2-2,5 \times 0,4-0,5 \mathrm{~cm}$, elíptico-lanceolada, base aguda, ápice agudo, margem inteira, alaranjado; sépalas laterais ca. $2-2,5 \times 0,4-0,5 \mathrm{~cm}$, elípticolanceoladas, base aguda, ápice agudo, margem inteira, alaranjadas; pétalas ca. 2-2,5 × 0,5 cm, elíptico-lanceoladas, base aguda, ápice agudo, margem inteira, alaranjadas; labelo ca. 2-2,5 $\times$ $1,2-1,4 \mathrm{~cm}$, trilobado, com um par de calos na base do disco central; lobos laterais obovoides, margem denteada a curto fimbriada, alaranjados; lobo central oblanceolado, margem denteada a curto fimbriada, ápice agudo, nervura central carenada da base do disco central até metade do comprimento do lobo central, alaranjado, com carena amarela; calos ca. $2 \times 0,5 \mathrm{~mm}$, estreito-elípticos, amarelos. Coluna 1,2-1,4 × 0,4 cm, adnata ao labelo, claviforme, alaranjada com ápice alvo. Antera ca. $1 \times 1 \mathrm{~mm}$, redonda, amarela. Polínias 4, ca. $1 \mathrm{~mm}$ compr., obovoides, fortemente achatadas, amarelas. Fruto não visto.

Material examinado: BRASIL. MATO GROSSO: Itaúba, Resgate de Flora da UHE Colíder, lote G de supressão, 9.V.2015, fl., M.E.Engels 3820 (HERBAM, MBM).

Epidendrum macrocarpum ocorre em Trindade e Tobago, Guiana Francesa, Guiana, Suriname, Venezuela, Colômbia, Equador, Peru e Brasil (Govaerts 2015). No Brasil ocorre nos estados do Amazonas, Amapá, Pará, Roraima, Alagoas, Bahia, Maranhão, Paraíba, Pernambuco e Rio de Janeiro (BFG 2015). No presente trabalho, E. macrocarpum é registrado pela primeira vez para o estado de Mato Grosso. Foi encontrada às margens do rio Teles Pires na Floresta Estacional Sempre Verde, região de ecótono entre os domínios de Cerrado e Amazônia, sendo pouco frequente. 
Pode ser caracterizada pelas flores ressupinadas e vistosas (ca. $5 \mathrm{~cm}$ diâm.), de coloração alaranjada (vermelha no Pará, ver Koch et al. 2014) e é comumente encontrada sobre formigueiros, e estes sobre ramos de árvores; labelo trilobado, margem serreada a curto fimbriada, e ápice agudo. Outras espécies congêneres simpátricas e que também ocorrem sobre formigueiros são E. flexuosum G. Mey. e $E$. smaragdinum Lindl. Epidendrum macrocarpum diferencia-se de E. flexuosum pelas flores alaranjadas e ressupinadas ( $v s$. róseas e não ressupinadas), e de E. smaragdinum pela inflorescência ascendente, flores alaranjadas e folhas com limbo elíptico ( $v s$. inflorescência descendente, flores verdes a verdes pintalgadas de castanho e folhas com limbo lanceolado). Encontrada com flor em novembro.

\section{Agradecimentos}

À Companhia Paranaense de Energia (COPEL), por permitir e incentivar a publicação dos dados aqui contidos. Ao Consórcio CIA Ambiental e seus colaboradores.

\section{Referências}

BFG. 2015. Growing knowledge: an overview of seed plants diversity in Brazil. Rodriguésia 66: 1085-1113.

Fidalgo, O. \& Bononi, V.L.R. 1989. Técnicas de coleta, preservação e herborização de material botânico. Reimpressão. Instituto de Botânica, São Paulo. 62p.

Govaerts, R. 2015. World checklist of Orchidaceae. Facilitated by the Royal Botanic Gardens, Kew. Disponível em <www.kew.org/wcsp/monocots $>$. Acesso em 22 novembro 2015.

Hagsáter, E. \& Soto-Arenas, M.A. 2005. Epidendrum L. In: Pridgeon, A.M.; Cribb, P.J.; Chase, M.W. \& Rasmussen, F.N. Genera Orchidacearum 4. Oxford University Press, Oxford. Pp. 236-251.

Koch, A.K.; Santos, J.U.M. \& Ilkiu-Borges, A.L. 2014. Sinopse das Orchidaceae holoepífitas e hemiepífitas da Floresta Nacional do Caxiuanã, PA, Brasil. Hoehnea 41: 129-148.

Silva, M.F.F.; Silva, J.B.F.; Rocha, A.E.S.; Oliveira, F.P.M.; Gonçalves, L.S.B.; Silva, M.F. \& Queiroz, O.H.A. 1995. Inventário da família Orchidaceae na Amazônia brasileira. Parte I. Acta Botanica Brasilica 9: 163-175.

Thiers, B. [continuamente atualizado]. Index Herbariorum: The Herbaria of the world. Disponível em $<$ http:// sweetgum.nybg.org/ih/>. Acesso em 9 abril 2016. 